\title{
Conexões Atlânticas: redes comerciais entre o Rio da Prata e os Estados Unidos (1790-1822)
}

Fabrício Prado*

Resumo: Este artigo analisa a presença comercial norte-americana no Rio da Prata, especificamente em Montevidéu entre 1790 e 1822. Nas primeiras décadas do século XIX, a presença comercial dos E.U.A. cresceu nos territórios americanos sob controle das monarquias ibéricas no Atlântico Sul. Comerciantes norte-americanos utilizaram diferentes estratégias comerciais para penetrar nos mercados espanhóis do Rio da Prata utilizando redes de comércio construídas no contexto do colonialismo ibérico. Durante a década de 1810, os comerciantes norte-americanos mantiveram as suas ligações com as monarquias espanhola e portuguesa, obtendo acesso legal aos portos ibero-americanos.

Palavras-chave: Mundo Atlântico. Comércio. Contrabando. Tráfico de escravos. Independências. Redes sociais. Rio da Prata.

Durante as últimas décadas do colonialismo espanhol e durante o período das guerras revolucionárias na América Latina (1810-1822), conflitos intermitentes interromperam o sistema comercial que ligava a Espanha a seus territórios americanos. Historiadores das processos de independência na América Latina enfatizam a importância da penetração comercial estrangeira na reconfiguração dos padrões comerciais no Atlântico Ibérico. O crescimento das

\footnotetext{
* Doutor em História da América Latina pela Emory University (Atlanta, EUA), Professor do College of William and Mary/Department of History. E-mail: fpprado@wm.edu
} 
trocas comerciais entre súditos de impérios atlânticos estrangeiros e suditos hispano-americanos é considerado crucial para a crise do império espanhol. Especialmente durante as Guerras Napoleonicas, o Império Espanhol permitiu o comércio com nações neutras nas suas colônias americanas. No Rio da Prata, o comércio com os nações neutras teve impacto econômico substancial (PRADO, 2015, p. 1-15). Os historiadores do Rio de Prata ressaltam o aumento do comércio com estrangeiros (especialmente britânicos), como cruciais para o processo da região de obter autonomia política e livre-comércio (FISHER, 1998, p. 459-479). Entretanto, apesar da pouca atenção por parte dos historiadores, na década de 1790 e durante as turbulentas duas primeiras décadas do século XIX, comerciantes americanos penetraram nos mercados hispano-americanos de forma significativa. O número de navios mercantes anglo-americanos em Montevidéu durante o período entre 1797 e 1822 é semelhante ao número de navios britânicos. Mais ainda, o comércio com norte-americanos experimentou picos durante os anos em que a cidade estava sob controle ibérico (até 1814 espanhol, e entre 1817-1822 luso-brasileiro). Dessa forma, o comércio Estadounidense-Montevideano foi crucial à manutenção de projetos políticos lealistas e monarquistas no Atlântico sul nas duas primeiras décadas do século XIX. ${ }^{1}$

Este artigo examina a presença comercial de comerciantes norte-americanos no Rio da Prata, especificamente em Montevidéu. Nas primeiras décadas do século XIX, a presença comercial dos EUA cresceu nos territórios americanos sob o controle das monarquias ibéricas no Atlântico Sul. Comerciantes norte-americanos penetraram nos mercados do Rio da Prata utilizando redes de comércio construídas no contexto do colonialismo ibérico. Durante a década de 1810, os comerciantes norte-americanos mantiveram as suas ligações com as monarquias espanhola e portuguesa, obtendo acesso legal aos portos ibero-americanos.

\section{$* * * * * *$}

Ao examinar o período tardo-colonial e os processos de independências no Rio da Prata, historiadores tenderam a concentrar-se na compreensão do crescimento e eventual preeminência do Império 
Britânico na região (BROWN, 2008). A presença norte-americana no Rio da Prata durante os últimos anos de domínio espanhol foi negligenciada por historiadores, em parte devido ao crescente envolvimento e presença dos Estados Unidos no México e no Caribe espanhol, e à proclamação da Doutrina Monroe na década de 1820 (CHANDLER, 1917). Arthur Whitaker, em seu influente livro Os Estados Unidos e a Independência da América Latina, sugere que entre 1810 e 1830, o público nos Estados Unidos "testemunhou a descoberta da América Latina” (WHITAKER, 1964, p. 6). Além disso, Whitaker enfatiza a importância dos laços político-econômicos entre norte-americanos e latino-americanos no período pós-Doutrina Monroe, sugerindo a existência de laços de solidariedade e apoio baseados em ideais republicanos. Em 1826, das dez legações diplomáticas norte-americanas, cinco estavam localizadas em novas repúblicas da América Latina (Buenos Aires, Bogotá, Santiago do Chile, México e Peru), enquanto as demais estavam todas na Europa (WHITAKER, 1964; FITZ, 2013). ${ }^{2}$ No entanto, uma análise mais aprofundada das relações comerciais entre os Estados Unidos e o Rio de la Prata mostra um quadro diferente. Durante o século XIX até a década de 1820, o comércio entre os Estados Unidos e os territórios hispano-americanos ainda estava profundamente ligado às monarquias ibéricas, no que os historiadores Paquette e Brown identificaram como continuidades após o colonialismo (PAQUETTE; BROWN, 2013).

$\mathrm{O}$ apoio e o reconhecimento norte-americano aos governos revolucionários na América do Sul não foi imediato. Como observa Jay Sexton, "nos anos de 1810 e 1820 os Estados Unidos ainda estavam no processo de consolidar sua independência e unidade interna” (SEXTON, 2013, p. 140). Além disso, os Estados Unidos do início do século XIX não era o país poderoso do final dos anos 1800 e tinha muito a temer dos impérios do Velho Mundo em relação ao seu status político e comercial. Nas duas primeiras décadas do século XIX, a “jovem república” da América do Norte encontrou não apenas maneiras de evitar as turbulências políticas derivadas das Guerras Napoleónicas utilizando-se das reformas comerciais liberalizantes do império espanhol, mas também conseguiu lucrar durante tal período de crise e instabilidade no Atlântico (SEXTON, 2013, p. 140-141; POMPEIAN, 2013). Negociar com 
comerciantes lealistas de Montevidéu e mais tarde com a administração monarquista luso-brasileira foi uma maneira diplomática e comercialmente segura de conduzir negócios na região. Manter os laços com os impérios ibéricos em perigo foi uma forma de penetrar os mercados sul-americanos contando com certa segurança legal e comerical sem perturbar as relações diplomáticas com outras potências europeias.

\section{A rivalidade entre Montevidéu e Buenos Aires na crise da monarquia espanhola}

O processo de independência no Rio da Prata foi complexo envolvendo várias facções regionais assim como agentes políticos internacionais. Enquanto Buenos Aires rompia com o domínio espanhol no início da década de 1810, Montevidéu permaneceu como um bastião lealista no Rio da Prata até 1814. Durante esse período, as elites de Montevidéu mantiveram a centralidade dos pueblos como fonte de soberania na área, o cabildo de Montevidéu exerceu influência sobre o território de toda a província, ao mesmo tempo que a exploravam as diversas brechas legais das políticas comerciais para aumentar o intercâmbio comercial com potências estrangeiras, especificamente com a comunidade comercial do Rio de Janeiro. A diferença nas maneiras como as elites políticas e econômicas de Buenos Aires e Montevidéu reagiram à crise monárquica em Espanha constituiram o ápice de disputas que já se desenrolavam desde as últimas décadas do período colonial.

A expulsão dos portugueses da Colônia do Sacramento, em 1777, provocou profundas mudanças econômicas, políticas e sociais no estuário do Rio da Prata. No final da década de 1770, quando Buenos Aires tornou-se a capital do recém-fundado Vice-reinado do Rio da Prata, Montevidéu tornou-se o principal porto atlântico no estuário do Rio da Prata. Montevidéu foi beneficiada pelas Reformas Bourbônicas tornando-se o porto de escala obrigatório para todos os navios que entram no Rio da Prata a partir do Oceano Atlântico, o único porto autorizado para o desembarque de escravos, e a base da frota naval espanhola Sul (e teve as Malvinas assim como os assentamentos patagônicos sob sua jurisdição). Além

Anos 90, Porto Alegre, v. 24, n. 45, p. 133-152, jul. 2017 
disso, Montevidéu foi sede da recém-criada Comandacia del Resguardo (órgão encarregado de reprimir o comércio ilegal, tanto marítimo como terrestre). Esta nova arquitetura imperial na região permitiu o surgimento de novos grupos comerciais e políticos baseados em Montevidéu, bem como exigiu que comerciantes de Buenos Aires passssem a manter procuradores e apoderados em Montevidéu, a fim de encaminhar as operações e agências comerciais através de autoridades Montevideanas.

O status imperial recém-adquirido não foi a única variável que contribuiu para o crescente papel comercial de Montevidéu no final do século XVIII. Após a queda da Colônia do Sacramento, Montevidéu tornou-se o centro das relações comerciais com os comerciantes portugueses e britânicos. Uma vez que as tropas espanholas conquistaram Sacramento em 1777, ricos e bem conectados comerciantes luso-platinos mudaram-se para Montevidéu, onde eles criaram alianças com a emergente elite Montevideana. Estes indivíduos ocuparam papéis estratégicos ao reconectar o comércio do Rio da Prata com a América portuguesa. Entre 1778 e 1806, mais de 500 embarcações navegaram entre a América portuguesa e Montevidéu, muitas vezes utilizando-se de diferentes pretextos legais para introduzir bens manufacturados europeus, açúcar, tabaco, e escravos em territórios espanhóis. Por volta de 1800, Montevidéu era o principal porto da região no que diz respeito ao comércio transatlântico, e as elites de Montevidéu contavam com redes de comércio de longa data com comerciantes luso-brasileiros.

As tensões entre as comunidades mercantis de Buenos Aires e Montevidéu emergiram durante a década de 1790 sob a forma de uma série de casos legais. Os comerciantes porteños questionaram legalmente o status de Montevidéu como porto de escala obrigatório para todos os navios atlânticos que entram no estuário, e questionaram também a jurisdição das autoridades Montevideanas sobre a repressão do contrabando marítimo. ${ }^{3}$ Apesar da dependência das elites comerciais de Montevidéu dos mercados e do capital de Buenos Aires, os comerciantes de Montevidéu não só defenderam o status legal do porto da Banda Oriental, mas também peticionaram à Coroa seu próprio Consulado de Comércio como uma tentativa de aumentar sua autonomia em relação às elites mercantis 
de Buenos Aires. A divergência de interesses entre as comunidades de Montevidéu e de Buenos Aires ficou ainda mais explícita depois das invasões britânicas de 1806-1807. Após a expulsão das forças invasoras de Buenos Aires, os comerciantes britânicos puderam permanecer em Montevideo por sete meses. Durante este período, os comerciantes de Montevidéu lucraram com a aquisição de bens britânicos a preços de pechincha. Essa manobra provocou revolta entre os círculos mercantis de Buenos Aires. ${ }^{4}$ Além disso, depois das invasões britânicas, Santiago de Liniers, vice-rei provisório do Vice-Reino do Prata, apoiado pelas elites e forças militares de Buenos Aires, tentou despojar Montevideo de sua condição de base da frota do sul, bem como da jurisdição da cidade sobre as Ilhas Malvinas e sobre os assentamentos patagônicos (STREET, 1959). Em 1808, as elites de Buenos Aires e de Montevidéu estavam em desacordo entre si em matérias políticas, legais e comerciais.

A crise política desencadeada pela invasão de Napoleão à Península Ibérica colocou as duas principais cidades portuárias do Rio da Prata em uma encruzilhada. Como resultado, o Cabildo Abierto de Montevidéu criou sua própria Junta que jurou lealdade à Junta Suprema de Sevilha, não reconhecendo a liderança de Buenos Aires. Tal dissensão foi reforçada em maio de 1810, quando os cabildantes de Montevidéu recusaram-se a seguir a radicalização da Junta de Buenos Aires e deposição do vice-rei Cisneros (1809-1810), o último vice-rei de Buenos Aires. A partir desse momento, Montevidéu tornou-se o centro do lealismo espanhol no Rio da Prata. As elites de Montevidéu proclamaram Montevidéu como a nova capital do vice-reinado, e, o então governador da cidade, Francisco Javier de Elío, como novo vice-rei do Rio da Prata. As elites de Montevidéu mantiveram as instituições administrativas do antigo regime, o projeto monárquico, e o princípio de soberania particular de los pueblos, com os cabildos como fonte de poder local. Este projeto, no entanto, não foi unânime, e no interior da Banda Oriental, projetos políticos rivais, republicanos, contaram com a adesão de um grande segmento da população rural.

Entre 1810 e 1814, Montevideo manteve-se fiel à monarquia espanhola e manteve relações comerciais ativas com a América portuguesa, com os Estados Unidos e com a Grã-Bretanha. ${ }^{5} \mathrm{O}$ bastião 
lealista de Montevideo caiu frente os ataques de forças revolucionárias de Buenos Aires (1814), posteriormente a cidade passou ao controle das forças da confederação de Artigas (1815), e por fim as forças do Império Luso-Brasileiro ocuparam Montevidéu e a Banda Oriental (1816). O controle luso-brasileiro sobre Montevideo e a Banda Oriental, sob a hábil liderança de Carlos Lecor, o Barão da Laguna, perdurou até a independência brasileira, em 1822. A independência formal do Brasil provocou uma divisão entre tropas leais ao rei lusitano e tropas portuguesas em favor do imperador brasileiro. Após a independência do Brasil, tropas leais à monarquia portuguesa ocuparam Montevidéu, deslocando as tropas brasileiras sob o comando de Lecor para o interior da Banda Oriental. O conflito entre estas duas facções durou até 1824 e foi um dos mais longos e violentos movimentos de resistência à independência brasileira. No rescaldo da "guerra civil" luso-brasileira, um grupo de caudilhos, os chamados 33 Orientais (1825), invadiu a Banda Oriental para acabar com o governo luso-brasileiro na região. Este foi o estopim da guerra entre o Brasil e as Províncias Unidas e, finalmente, culminou na independência do Uruguai em 1828. Durante a ocupação luso-brasileira (1817-1822), houve um aumento significativo do comércio com portugueses, britânicos e norte-americanos. Essas relações comerciais tiveram sua origem nas últimas décadas do período colonial.

\section{Presença Comercial Estadounidense no Rio da Prata até 1808}

Entre 1778 e 1810, um mínimo de 740 navios foram envolvidos no comércio trans-imperial com a região do Rio da Prata (Montevidéu). Deste total, 286 navios eram portugueses (38,6\%), 271 espanhóis (36,6\%), 86 anglo-americanos (11,6\%), 92 navios britânicos $(12,4 \%), 3$ franceses $(0,5 \%)$ e 2 dinamarqueses. Em alguns casos, não havia informação, e, em outros casos, os documentos encontravam-se deteriorados, de modo que a informação acerca da bandeira de origem não era legível em 42 registros. ${ }^{6}$

A prevalência de navios portugueses e espanhóis deve ser considerada no contexto de conflitos atlânticos intermitentes, comércio 
neutro, e políticas comerciais mais livres em relação ao tráfico de africanos escravizados. Durante este período, comerciantes do Rio da Prata aproveitaram as leis espanholas permitindo comércio com nações neutras e usaram navios portugueses para enviar mercadorias, prata e informações para Espanha sob a proteção da frota luso-brasileira. A presença norte-americana no Rio da Prata deve ser entendida no contexto do comércio com nações neutras e as reformas liberalizantes do império espanhol no período tardo colonial.

Os comerciantes anglo-americanos apareceram em números significativos na região munidos de licenças comerciais espanholas obtidas sob as leis de comércio neutro de 1797 (ALDEN, 1969, p. 267-288). Os comerciantes norte-americanos foram rápidos em compreender as novas oportunidades comerciais em territórios espanhóis; no entanto, apesar das medidas liberalizantes do império espanhol, havia risco significativo nessas operações. Em 1801/1802, vários comerciantes norte-americanos enfrentaram problemas com autoridades espanholas no Rio da Prata. Como parte de uma demonstração de força das autoridades locais em relação a prescrição dos decretos comércio neutro em 1800, as autoridades rio-platenses embargaram diversos navios mercantes dos EUA no Rio da Prata, impedindo-os de continuar suas viagens. ${ }^{7} \mathrm{O}$ incidente de 1802 apareceu nas páginas de jornais dos EUA em diferentes regiões. ${ }^{8}$

O incidente dos navios embargados ilumina o escopo das atividades mercantes americanas no Rio da Prata. O incidente envolveu cerca de 44 navios americanos no Rio da Prata (incluindo embarcações em Buenos Aires e Montevideo). A maioria das embarcações embargadas eram provienientes de portos na Nova Inglaterra: 22 de Boston, 5 de Rhode Island e um navio de New Hampshire, Massachusetts, e Nova York, respectivamente. Quinze navios da Filadélfia encontraram dificuldades legais no Rio da Prata. Nas páginas do New York Evening Post, um "respeitável cavalheiro americano em Buenos Aires", exigiu que o governo dos EUA intervisse diretamente junto a corte Espanhola a favor dos comerciantes americanos. ${ }^{9} \mathrm{O}$ artigo mencionava 32 embarcações americanas confiscadas pelas autoridades espanholas que transportavam "bens no valor de três milhões de dólares". ${ }^{10}$ A tonelagem média desses navios norte-americanos era de aproximadamente 330 toneladas, o que indica uma 
grande capacidade de carga dos navios estadounidenses, permitindo longas viagens inter-oceânicos com pontos de coméricio multi-lateral, envolvendo portos e agentes em diferentes impérios. ${ }^{11}$ Muitos destes navios estavam no meio de viagens mais longas, visitando outros portos na América do Sul e na Ásia (CHANDLER, 1917, p. 40). Como resultado, o embargo de embarcações dos EUA no Rio da Prata trazia consequências ainda mais significativas, para além do Rio da Prata, visto da impossibilidade dos barcos norte-americanos prosseguirem para seus próximos portos de escala. O incidente foi resultado da determinação das autoridades espanholas em suprimir os comerciantes que estendem a validade de licenças de comércio neutral. Este episódio primeiro e acima de tudo ensinou comerciantes americanos da importância de ter pelo menos pretextos legais e conexões locais com as autoridades hispano-americanas.

Com o restabelecimento de licenças comerciais neutras, em 1805, o comércio americano no Rio da Prata experimentou um rápido ressurgimento. Durante 1805 e 1806, 46 navios americanos entraram no Porto de Montevidéu. Os navios norte-americanos entraram legalmente no Rio da Prata sob licenças espanholas para o comércio com paises neutros. As concessão de licenças de comércio neutral para navios dos EUA permitindo-os atracar em Montevidéu revela a complexa relação comercial envolvendo comerciantes norte-americanos e a Coroa Espanhola. Navios norte-americanos recebiam licenças para transportar mercadorias de Montevidéu para La Habana - especialmente tasajo, para o transbordo de mercadorias, prata e informações para a Europa, e para o comércio regular de frutos do país. Em 1806, o comerciante da Filadélfia, Frances Brenil, obteve licença para adquirir couros e charque em Montevidéu como recompensa por fornecer trigo e outros bens nos anos anteriores para Porto Rico. ${ }^{12}$ Os comerciantes americanos compreederam a importância de artifices legais quando tratando com súditos da monarquia espanhola a fim de assegurar a segurança de suas operações sul-americanas. Além disso, os comerciantes anglo-americanos estavam lucrando com o abastecimento das colônias espanholas nas Américas e simultaneamente obtendo acesso aos seus mercados.

Comerciantes americanos também se utilizaram da liberalização no comércio de escravos para explorar as oportunidades comerciais 
nas colônias hispano-americanas. Dos 86 navios norte-americanos que entraram no estuário do Rio da Prata entre 1797 e 1810, 58 estavam envolvidos em operações de escravatura e 26 desses navios também carregavam cargas comerciais junto com escravos (embora tecnicamente proibido pelas leis espanhola). Embora apenas 48 navios tenham saído diretamente da África rumo ao Rio da Prata, outros 8 navios negreiros tocaram outros portos das Américas (Rio de Janeiro, Bahia). Outros dois barcos escravistas dos EUA embarcaram pessoas escravizadas no Rio de Janeiro para se dirigirem posteriormente ao Rio da Prata. Das viagens escravistas americanas, uma foi contrabando, visto que desembarcou escravos em 1809, após a proibição estadounidense do tráfico em $1808 .{ }^{13} \mathrm{O}$ tráfico de escravos nos Estados Unidos foi responsável por 8,2\% das viagens escravas totais ao Rio da Prata, ou 11\% das viagens para Montevidéu entre 1780 e 1809. Outras duas viagens chegaram durante a ocupação britânica de Montevideo em 1807. ${ }^{14}$

Quanto aos portos de origem das viagens escravistas dos Estados Unidos, a Nova Inglaterra foi a região de origem de aproximadamente 56\% das viagens negreiras dos Estados Unidos ao Rio da Prata (31). Rhode Island (Providence, Bristol, Newport) sozinha foi a região de origem de 23 viagens escravistas (40\%). Outros portos que enviaram navios negreiros para o Atlântico Sul incluíam Portland, Maine e Boston, MA. O porto de Charleston foi a origem de 6 viagens escravistas, e Portsmouth, uma. Durante o período de 21 anos em que foram registradas expedições escravistas dos Estados Unidos para o Atlântico sul, Rhode Island estava no centro do tráfico de escravos dos Estados Unidos para o Rio da Prata. Embora o Rio da Prata não fosse uma região central para os trafiantes de escravos dos Estados Unidos (os traficantes de escravos dos Estados Unidos apareceram esporadicamente no comércio platino), embarcações de Rhode Island chegaram à região entre 1797 e 1807 (MARQUES, 2016, p. 23). Tais padrões observados para o tráfico de escravos dos EUA ao Rio da Prata refletem aproximadamente o padrão geral de viagens de escravos organizadas nos Estados Unidos durante o período. 
Atestando a natureza trans-imperial e multi-lateral dos traficantes de escravos dos Estados Unidos, as embarcações estadounidenses utilizavam portos ibéricos independentemente de serem portugueses ou espanhóis. Enquanto duas viagens começaram diretamente do Rio de Janeiro levando escravos para o Rio da Prata, outras 8 expedições utilizaram o Rio de Janeiro como escala, seja a caminho para a costa africana, ou no retorno da África a caminho do Rio da Prata. Outras embarcações dos Estados Unidos também aportaram na Bahia quando a caminho do Rio da Prata. ${ }^{15}$ Depois de entrar em portos brasileiros, os navios dos Estados Unidos eram normalmente autorizados a permanecer por um período variando de dez dias a um mês inteiro, e recebiam autorizações limitadas para negociarem (normalmente relacionadas com reparos ou aquisição de suprimentos). Esse padrão se encaixa no movimento geral do tráfico de escravos nos Estados Unidos no período do fortalecimento das ligações com os circuitos brasileiros de comércio de escravos (MARQUES, 2015, p. 53-55).

\section{Comércio Estadounidense no Rio da Prata Durante a longa década revolucionária (1808-1822)}

Na longa década de 1810, a presença norte-americana tendeu a coincidir com o controle espanhol sobre Montevidéu (1810-1814), ou luso-brasileiro no Rio da Prata (1817-1822). As Tabelas 1 e 2 mostram um claro aumento no número de embarcações norte-americanas que entraram oficialmente no porto de Montevidéu durante anos de controle lealilsta e monárquico sobre Montevidéu e Banda Oriental. 
Conexões Atlânticas: redes comerciais entre o Rio da Prata...

Tabela 1 - Ships Entering the Port of Montevideo

\begin{tabular}{c|c|c|c|c|c|c}
\hline Year/Flag & Spanish & Portuguese & English & US & Other & Total \\
\hline $\mathbf{1 8 0 5}$ & 7 & 18 & 0 & 17 & 6 & 48 \\
\hline $\mathbf{1 8 0 6}$ & 21 & 19 & 0 & 29 & 7 & 76 \\
\hline $\mathbf{1 8 0 7} *$ & 0 & 2 & 0 & 0 & 0 & $2 *$ \\
\hline $\mathbf{1 8 0 8}$ & 58 & 11 & 10 & 5 & 1 & 85 \\
\hline $\mathbf{1 8 0 9}$ & 83 & 23 & 29 & 9 & 1 & 145 \\
\hline $\mathbf{1 8 1 0}$ & 118 & 30 & 56 & 24 & 1 & 229 \\
\hline $\mathbf{1 8 1 1}$ & 91 & 25 & 23 & 50 & 2 & 191 \\
\hline $\mathbf{1 8 1 2}$ & 60 & 26 & 10 & 9 & 0 & 105 \\
\hline $\mathbf{1 8 1 3}$ & 37 & 40 & 0 & 0 & 0 & 77 \\
\hline $\mathbf{1 8 1 4}$ & 14 & 21 & 3 & 0 & 0 & 38 \\
\hline
\end{tabular}

Fonte: AGNU - ExAGA Libro 95 - Aduana, Libro de Entrada de Embarcaciones, * Missing Data

Tabela 2 - Ships Entering the Port of Montevideo

\begin{tabular}{c|c|c|c|c|c|c|c|c|c}
\hline & Spanish & Port & Brit. & US & French & Nac. & BsAs & Other & Total \\
\hline $\mathbf{1 8 1 7}$ & 0 & 13 & 13 & 6 & 2 & - & 13 & 0 & 47 \\
\hline $\mathbf{1 8 1 8}$ & 2 & 52 & 17 & 12 & 5 & - & 18 & 3 & 109 \\
& & $48 \%$ & $16 \%$ & $11 \%$ & $5 \%$ & & $16 \%$ & $3 \%$ & \\
\hline $\mathbf{1 8 1 9 *}$ & 0 & 4 & 4 & 2 & - & - & - & $0 *$ & 10 \\
\hline $\mathbf{1 8 2 0}$ & 0 & 123 & 49 & 32 & 20 & - & $166 \%$ & $145 \%$ & 254 \\
& & $48 \%$ & $19 \%$ & $13 \%$ & $8 \%$ & & & & \\
\hline $\mathbf{1 8 2 1}$ & 0 & 121 & 90 & 57 & 26 & 22 & 18 & 25 & 359 \\
& & $34 \%$ & $25 \%$ & $16 \%$ & $7 \%$ & $6 \%$ & $5 \%$ & $7 \%$ & \\
\hline $\mathbf{1 8 2 2}$ & 1 & 0 & 73 & 68 & 18 & 187 & 25 & 11 & 383 \\
& & & $19 \%$ & $18 \%$ & $5 \%$ & $48 \%$ & $6 \%$ & $3 \%$ & \\
\hline
\end{tabular}

Fonte: AGNU - ExAGA Libro 99 Aduana, Libro de Entrada de Embarcaciones, * Missing data.

Anos 90, Porto Alegre, v. 24, n. 45, p. 133-152, jul. 2017 
Entre 1810 e 1812, 83 navios norte-americanos entraram no porto de Montevidéu. Embarcações comerciais dos Estados Unidos utilizavam ainda das prerrogativas do comércio neutral entre 1810 e 1814. Durante esse período, os comerciantes norte-americanos desempenharam um papel crucial no fornecimento de trigo, munições e armas aos exércitos que lutavam contra Napoleão na Península Ibérica. Como resultado, negociantes estadounidenses utilizaram-se desta conjuntura para penetrar também em outros mercados hispano-americanos. Para os comerciantes montevideanos, o comércio com os anglo-americanos representava a possibilidade de manter o comércio trans-imperial enquanto a cidade permanecia leal à Espanha. Em 1810, os navios norte-americanos constituíam a terceira maior frota estrangeira em Montevidéu. Em 1811, os comerciantes dos EUA foram a maior frota mercante estrangeira, aproximadamente 1 em cada 4 navios anconrados em Montevidéu. Enquanto as guerras napoleónicas interromperam as tradicionais rotas comerciais na Europa, os comerciantes anglo-americanos encontraram condições para lucrar. Em 1811, os navios britânicos representaram apenas $12 \%$ do movimento anual do porto, contra o forte aumento da presença EUA-América (26\%). A guerra entre os Estados Unidos e a Grã-Bretanha, em 1812, teve efeito adverso sobre o comércio norte-americano no Rio da Prata. O ano de 1812 foi marcado por um declínio geral no movimento de embarcações no porto de Montevevideo (apenas 105, em comparação com 191 em 1812). Os navios americanos representaram $9 \%$ do movimento naval Atlântico, enquanto os navios britânicos compreendiam mais 10\% do movimento do porto de Montevidéu.

Os anos 1814 e 1816 foram marcados por intensa turbulência política e econômica no Rio da Prata. Em 1814, o governo lealista de Montevidéu caiu sob o controle das forças revolucionárias de Buenos Aires. Quase um ano depois, as tropas revolucionárias da Confederação de Artigas ocuparam a cidade. Em 1817, por convite/ pedido das elites mercantis de Montevidéu, tropas luso-brasileiras invadiram e ocuparam Montevidéu e a Banda Oriental. Em 1820, 
a Banda Oriental foi formalmente anexada ao Império Luso-Brasileiro como a Província Cisplatina, com sua capital em Montevidéu.

A ocupação e anexação de Montevidéu e da Banda Oriental pelo Império Luso-Brasileiro representou os interesses das elites mercantis de Montevidéu envolvidas no comércio trans-imperial. O projeto monárquico para a área envolveu a manutenção de instituições coloniais (incluindo Cabildos, autoridades administrativas e instituições comerciais). Para as elites mercantis Montevideanas, tornar-se uma província do Império Luso-Brasileiro era uma forma de manter redes comerciais com a América portuguesa e países estrangeiros no Atlântico, especialmente Inglaterra e Estados Unidos.

O movimento de navios mercantes norte-americanos no Rio da Prata experimentou um significativo incremento durante o período da Cisplatina. Entre 1818 e 1822, os navios norte-americanos constituíram a segunda maior frota mercante estrangeira em Montevidéu, atrás apenas dos navios britânicos. ${ }^{16}$ Durante este período, quase metade dos navios que chegam a Montevidéu eram luso-brasileiros (navios luso-brasileiros aparecem sob a bandeira "Nacional"). No entanto, a maior parte dos navios luso-brasileiros eram navios de tamanho médio a pequeno, utilizados principalmente na navegação costeira. A reduzida tonelagem das embarcações luso-brasileiras fica explicita quando comparada com a tonelagem média de navios britânicos ou americanos que operavam no Rio da Prata. A tonelagem média para os navios que saíram de Buenos Aires em 1823 indicou que a em média embarcações portuguesas tinham capacidade de 97 toneladas, contra 225 toneladas por navio norte-americano, e 166 toneladas por navio inglês (BARBA, 1978, p. 60-70). Dessa forma, apesar do numero total de embarcaões britânicas e norte-americanas ter sido inferior ao numero de barcos luso-brasileiros, a grande capacidade dos barcos provienientes do Atlatico norte também indicava, especialmente no caso dos navios norte-americanos, que eles estavam envolvidos em comércio multilateral, em viagens longas, comprando e vendendo mercadorias em diferentes portos ao longo da viagem.

O itinerario oficial dos navios norte-americanos que entraram no porto de Montevidéu entre 1818 e 1822 revelam um padrão multilateral de comércio que ligava vários portos da América do 
Sul, da América do Norte, do Caribe, da Europa e da Ásia. Os navios americanos tendiam a fazer escala em vários portos durante uma viagem, adquirindo bens e produtos em função da demanda comercial do(s) próximo(s) portos(s), ou produtos de valor comercial no porto de retorno final da viagem. Navios norte-americanos poderiam deixar Filadélfia ou Boston, parar em Cuba, no Rio de Janeiro, adquirir açúcar, rum e vendê-los no Rio da Prata. Na viagem de volta, Hamburgo poderia ser um porto de escala, onde Cascarilla (casca Cinchona para produção de quinino) e couros estavam em demanda. Entretanto, a maioria dos navios americanos que zarpou para Montevidéu nas décadas de 1810 e 1820 declarou intenções de retornar para um porto nos Estado Unidos. Cerca de um terço dos navios norte-americanos deixaram o porto de Montevidéu declarando como destino Buenos Aires, Colónias Estrangeiras, Hamburgo, La Habana ou Rio de Janeiro. Entre 1810 e 1822, aproximadamente dois terços de todos os navios norte-americanos que entraram em Montevidéu pararam em um ou mais portos de escala no caminho para o Rio da Prata. Os portos ao longo da costa do Brasil (Rio e Bahia) foram os portos mais comumente utilizados, mas La Habana e até Buenos Aires foram freqüentes pontos de escala. O comércio multilateral trans-imperial foi um novo padrão nas operações comerciais no estuário do Rio da Prata se comparado com os padrões de comércio britânico e luso-brasileiro.

A análise das cargas comerciais dos navios norte-americanos que partiram desde o porto de Montevidéu permite uma visão mais detalhada dos padrões de comércio entre Montividéu e os Estados Unidos. Os navios norte-americanos que saíam do Rio da Prata, com destino direto aos Estados Unidos costumavam levar couro em pelo, chapas (couros cortados especificamente para uso como correias para motores) e cera. Mais ainda, peles de outros animais e outras mercadorias como lã, cobre e sabão também eram produtos freqüentes exportados de Montevidéu para os Estados Unidos. Em mais de uma dúzia de ocasiões, navios norte-americanos transportaram charque de Montevidéu para Cuba. Tais itinerarios e operações comerciais revelam o grau de envolvimento norte-americano em redes que permeavam as monarquias ibéricas. Os navios norte-americanos não só adquiriam produção agrícola de áreas sob controle 
espanhol ou português no Rio da Prata, mas também asseguraram o abastecimento de outras colonias do império espanhol, neste caso Cuba, com alimentos.

Os comerciantes norte-americanos também estiveram envolvidos no fornecimento de alimentos e outros produtos atlânticos em Montevidéu. Durante a década de 1810 e início da década de 1820, grandes quantidades de trigo, tabaco, açúcar e móveis entraram no Rio da Prata através de embarcações norte-americanas. Farinha, vinho, cachaça e tabaco eram as principais commodities introduzidas no Rio da Prata por comerciantes norte-americanos. Móveis, papel, têxteis e outros bens manufaturados também eram entradas freqüentes nos registros aduaneiros.

A importância da introdução regular do trigo americano em uma região que sofria com conflitos armados há quase uma década não pode ser subestimada. A disponibilidade de alimentos e "vícios" (aguardiente, tabaco) contribuiu não apenas para a estabilidade social e política, mas também para o rendimento das administrações lealistas e monárquicas. De 1810 a 1814, Montevidéu esteve sob cerco militar, o que tornou ainda mais crucial a introdução de gêneros alimentícios para a manutenção do projeto monarquista na cidade-porto. Neste período, a produção agrícola caiu para níveis insuficientes para abastecer a população da região. Dessa forma, o trigo norte-americano desempenhou um papel crucial na manutenção da população de Montevidéu, assim como a manutenção da cidade como um bastião monárquico e anti-revolucionário no Atlântico Sul.

O comércio multilateral entre os EUA e o Rio da Prata teve um significado mais profundo do que o apoio econômico de áreas sob o domínio ibérico. Os navios norte-americanos ligaram territórios hispano-americanos (Cuba, Porto Rico, Montevidéu) e outras regiões do Atlântico (Boston, Rio de Janeiro, Curaçao) durante um período de extremo risco para navios que desfraldavam a bandeira espanhola. Os navios norte-americanos transportavam informações, mercadorias e moviam prata entre territórios espanhóis. Como resultado, os navios mercantes norte-americanos contribuíram para a manutenção do Império Espanhol nas Américas e, mais tarde, para a província de Cisplatine. 


\section{Conclusão}

Durante as últimas décadas do período colonial comerciantes norte-americanos se converteram em importantes agentes comerciais no Rio da Prata. Tal tendência persistiu durante a década revolucionária de 1810. O comércio entre os Estados Unidos no Rio da Prata floresceu durante períodos de controle ibérico na região. Essa tendência reflete o cuidadoso posicionamento político dos comerciantes norte-americanos, bem como uma profunda preocupação com a segurança jurídica das transações. O status de nação neutra permitiu aos comerciantes estadounidenses penetrar nos mercados sul-americanos sob a proteção dos impérios ibéricos nas Américas. Tal comércio se revelou crucial para a manutenção de projetos políticos lealistas e monárquicos no Rio da Prata, especificamente para os projetos políticos apoiados pelas elites de Montevidéu. Apesar da crescente presença de comerciantes britânicos e franceses na região no final dos anos 1820 e 1830, as redes de comércio entre o Atlantico Norte e o Atlantico sul desempenharam um papel crítico para a manutenção do colonialismo ibérico desde o final da década de 1790 até o início da década de 1820.

\section{ATLANTIC CONNECTIONS: RIO DE LA PLATA AND UNITED STATES COMMERCIAL NETWORKS (1790-1822)}

Abstract: This article examines the United States commercial presence in Rio de la Plata, specifically in Montevideo, between 1790 and 1722. In the first decades of the nineteenth century, US commercial presence grew in American territories under the control of Iberian monarchies in the South Atlantic. United States merchants used different commercial strategies to penetrate the Spanish markets of Rio de la Plata using commercial networks built in the context of Iberian colonialism. During the decade of 1810, the North American merchants maintained their connections with the Spanish and Portuguese monarchies, obtaining legal access to the Ibero-American ports.

Keywords: Atlantic World. Commerce. Contraband trade. Independence. Slave trade. Networks. Rio de la Plata. 


\section{Notas}

${ }^{1}$ Utilizo o termo "lealistas" para referir aos grupos apoiadores das Juntas espanholas e Fernando VII durante os anos 1810-1814. Utilizo o termo monarquistas em referência aos grupos apoiadores da administração Luso-Brasileira, incluindo grupos que viam na solução Luso-Brasileira um arranjo temporario até que um novo arranjo monárquico com a Espanha fosse possível. Ver: DI MEGLIO, Gabriel. Viva el Bajo Pueblo. Buenos Aires: Prometeo Libros, 2006. FREGA, Ana. Historia Regionaly Independecia Nacional. Montevideo: EBO, 2009, especialmente o capítulo acerca da conspiração monarquista de 1817-1821.

${ }^{2}$ Recentemente, Caitlin Fitz demosntrou a importância do apoio da opinião pública norte-americana aos esforços revolucionários e republicanos na América Latina. Jornais, associações civis, e até mesmo a re-nomeação de cidades e batismo de bebês celebrando cidades hispano-americanas e lideres revolucionários. Caitlin Flitz, Our Sister Republics...

3 AGN Sala IX 1.2.5 - October, 8, 1804, and AGI Buenos Aires Gobierno Leg 346 - February, 27, 1797. Para uma análise detalhada dos conflitos entre as comunidades de Buenos Aires e Montevideo, ver: PRADO, 2015.

${ }^{4}$ JCB - Documentos 1807-9 B81 A692c v. 1, 1-Size. Observaciones de los Recientes Acontecimentos en Montevideo. Anonymous. c. 1810. O autor anônimo, escrevendo desde Buenos Aires se refere aos comerciantes montevideanos como “iReptiles de la sociedad!.” De forma menos dramática: MAWE, John. Voyage in the Interior of Brazil, particularly in the Gold and Diamond Districts of that Country, by Authority of the Prince Regent of Portugal, Including a Voyage to the Rio de la Plata, and a Historical Sketch of the Revolucion of Buenos Ayres. London: Longman, Hurst, Rees, Orme and Bronw, Paternoster-Row, 1812, p. 40-53. Mawe também menciona um grande contigente de ex-soldados britânicos que tomou residência em Montevideo após jurar fielidade ao Rei de Espanha. Mawe comenta que podia identifica-los pois esses individuos ainda utilizavam os velhos uniformes das forças britânicas. ${ }_{5}^{5}$ John Carter Brown Library, B81 A692c v. 1, 1-Size - REGLAMENTO Formado por la Junta de Comercio de Montevideo Sobre El Metodo y Formalidades que Deben Observarse en las Expediciones Procedentes de Extrangeros aprobado por el Superior Gobierno. 1811.

${ }^{6}$ AGNM, EHG, Libros 96 - Salida de Buques; AGNM, EHG, Libro 99 Entrada de Buques; Prado, Edge of Empire... p. 67.

${ }^{7}$ Neutral Trade policy has officially ended in 1799; however, neutral trade has continued despite protest of metropolitan authorities.

${ }^{8}$ Early American Newspapers. The New-York Evening Post, 10 jun. 1802; Albany Gazette, 15 jul. 1802; Norwich Courier, 07 jul. 1802; Pbilladelphia Gazette, 30 ago. 1802; Salem Register, 28 ago. 1802; The United States Oracle, and Portsmouth Advertiser, 24 jul. 1802.

Anos 90, Porto Alegre, v. 24, n. 45, p. 133-152, jul. 2017 
${ }^{9}$ Evening Post, New York, 14 jul. 1802.

${ }^{10}$ Albany Gazette, 15 jul. 1802.

${ }^{11}$ Albany Gazette, 15 jul. 1802.

${ }^{12}$ Archivo General de Indias, Buenos Aires 139, En la Fragata Americana... 10 fev. 1806.

${ }^{13}$ Quarenta e oito expedições escravistas aparecem em Voyages: The Trans-Atlantic Slave Trade Database Online, os números que utilizo neste artigo incluem informação a respeito de viagens adicionais. Agradeço a Alex Borucki a indicação de várias dessas fontes, especialmente sobre a viagem de 1809. AGN-U Libro 95, AGN-A Sala IX 3.1.7, 18.8.1, 2.10.2.

${ }^{14}$ The Southern Star. Montevideo, 1807.

${ }^{15}$ Rhode Island Historical Society, Ship Resource, Reel 20. TANNER, Earl C. A Question as to Buenos Aires: Rhode Islanders in the River Plate Slave Trade 1807/07. Rhode Island History, 1964.

${ }^{16}$ AGNU - Ex-AGA - Libros de Entrada de Buques. Libro 95 e Libro 99.

\section{Referências}

ALDEN, Dauril. Yankee Sperm Whalers in Brazilian Waters, and the Decline of the Portuguese Whale Fishery (1773-1801). The Americas, v. 20, n. 3, p. 267-288, jan. 1964.

BARBA, Enrique. Relacion del Comercio de Buenos Aires. Buenos Aires: Academia Nacional de Historia, 1978.

BORUCKI, Alex. The Slave Trade to Rio de la Plata, 1777-1812: Trans-Imperial Networks and Atlantic Warfare. Colonial Latin American Review, v. 20, n. 1, p. 81-107, abr. 2011.

BROWN, Matthew. Informal Empires. London: Wiley-Blackwell, 2008.

CHANDLER, Lyon. Inter-American Acquaintances. The Univ. Press of Sewanee Tennessee, 1917.

DI MEGLIO, Gabriel. Viva el Bajo Pueblo. Buenos Aires: Prometeo Libros, 2006. FISHER, John. Commerce and Imperial Decline: Spanish Trade with Spanish America 1797-1820. Journal of Latin American Studies, v. 30, p. 459-479, 1998.

FREGA, Ana. Historia Regional y Independecia Nacional. Montevideo: EBO, 2009. FREGA, Ana. Pueblos y Soberania en la Revolucion Artiguista. Montevideo: Ed. De la Banda Oriental, 2007.

LYNCH, John. Latin American revolutions, 1808-1826: Old and New World origins. Norman: University of Oklahoma Press, 1994. 
MARQUES, Leonardo. The US and the Atlantic Slave Trade. New Haven: Yale University Press, 2015.

MAWE, John. Voyage in the Interior of Brazil, particularly in the Gold and Diamond Districts of that Country, by Authority of the Prince Regent of Portugal, Including a Voyage to the Rio de la Plata, and a Historical Sketch of the Revolucion of Buenos Ayres. London: Longman, Hurst, Rees, Orme and Brown, Paternoster-Row, 1812.

PAQUETTE, Gabriel; BROWN, Matthew. Connections after Colonialism. Oxford: University of Alabama Press, 2013.

POMPEIAN, Edward. Spirited Enterprises: Venezuela, the United States, and the Independence of Spanish America, 1789-1824. The College of William and Mary, Ph.D. Dissertation, 2013.

PRADO, Fabrício. Edge of Empire: Atlantic Netwroks and Revolution in Bourbon Rio de la Plata. Oakland: UC Press, 2015.

SEXTON, Jay. An American System: the North American Union and Latin America in the 1820s. In: PAQUETTE, Gabriel; BROWN, Matthew. Connections after Colonialism. Oxford: University of Alabama Press. 2013.

STREET, John. Artigas and the Emanciaption of Uruguay. Cambridge: Cambridge University Press, 1959.

TANNER, Earl C. A Question as to Buenos Aires: Rhode Islanders in the River Plate Slave Trade 1807/07. Rhode Island History, 1964.

WHITAKER, Arthur. The United States and the Independence of Spanish America. New York: Norton \& Co., 1964.

Recebido em: 30/12/2016 Aprovado em: 15/03/2017 